\title{
New global physical activity guidelines for a more active and healthier world: the WHO Regional Offices perspective
}

\author{
Riitta-Maija Hämäläinen ำ , ${ }^{1}$ João Breda, ${ }^{2}$ Fabio da Silva Gomes, ${ }^{3}$ \\ Gyanendra Gongal, ${ }^{4}$ Wasiq Khan, ${ }^{5}$ Romeu Mendes (ㄷ) ${ }^{2}$ \\ Leo Nederveen, ${ }^{3}$ Nivo Ramanandraibe, ${ }_{1}^{6}$ Binta Sako, ${ }^{7}$ Stephen Whiting ${ }^{2}$
}

The WHO Global Action Plan on Physical Activity 2018-2030: more active people for a healthier world (GAPPA) ${ }^{1}$ was launched in 2018 to support countries to achieve a $15 \%$ relative reduction in prevalence of insufficient physical activity (PA) by 2030 . GAPPA has raised awareness of the need for a whole-of-society response and a systems-based approach to achieve a paradigm shift in supporting all people to be physically active across the life course. Updating the WHO global PA guidelines was a key proposed action of this plan and requested by WHO Member States in the 2018 World Health Assembly.

Guidelines are an important part of PA policy development. Implementing evidence-based PA guidelines can improve health outcomes at individual and population levels. For example, specific recommendations can help health professionals to assess PA and sedentary behaviour as a vital sign and provide counselling towards more physical active lifestyle to their patients in the primary care. More broadly, guidelines are essential tools for conducting monitoring and surveillance of PA and to help policymakers develop optimal policies and programmes to improve public health. ${ }^{1}$ However, the existence of PA guidelines at global level, or even national level, is alone unlikely to prompt sustainable changes in PA behaviours of populations. To have an

\section{${ }^{1}$ World Health Organization Regional Office for the Western Pacific, Manila, Philippines \\ ${ }^{2}$ World Health Organization Regional Office for Europe, Copenhagen, Denmark \\ ${ }^{3}$ Pan American Health Organization, Washington, DC, USA \\ ${ }^{4}$ World Health Organization Regional Office for South- East Asia, New Delhi, India \\ ${ }^{5}$ World Health Organization Regional Office for the Eastern Mediterranean, Cairo, Egypt \\ ${ }^{6}$ World Health Organization Regional Office for Africa, Brazzaville, Congo \\ ${ }^{7}$ World Health Organization Regional Office for Africa, Inter-country Support Team for West Africa, Ouagadougou, Burkina Faso}

Correspondence to Dr Riitta-Maija Hämäläinen WHO Regional Office for the Western Pacific, Manila, Philippines; hamalainenr@who.int impact, guidelines must be tailored to the country context and be used by national, regional and local organisations when developing, implementing and evaluating policies and interventions.

WHO develops guidelines for a global audience. Taking into consideration the different contexts, during the development of the guidelines, the six WHO Regional Offices, with the support of WHO Headquarters, organised online workshops in each region that brought together representatives from countries to plan the adoption and adaptation of global guidelines at the national level. In addition, the dissemination and communication of national guidelines, at national and subnational levels within health systems and in the complex interconnections between public health and multisectoral institutions, were examined and broadly discussed.

The regions share similar challenges to the adoption, adaptation and dissemination of PA guidelines, which need to be addressed to enable countries to scale their actions on PA. These include: the need for contextualisation of the guidelines to respond to specific populations within regions and countries; addressing the barriers to PA facing women, elderly, persons with disabilities and chronic diseases, and low-income populations' participation; lack of local data on determinants of behavioural change and inadequate infrastructure. Other challenges relate to the health systems such as multiple competing priorities in already overstretched national non-communicable diseases prevention and control programmes; barriers to collaboration with stakeholders to support adaptation and implementation of the guidelines; and insufficient human and financial resources particularly in low resource contexts.

Since the launch of the 2010 WHO Global Recommendations on Physical Activity, ${ }^{2}$ the evidence of the benefits of PA for the prevention and treatment of diseases and in promoting health and wellbeing has been unquestionably strengthened. $^{3} 4$ Besides the effect on health, promoting PA will help to achieve many of the 2030 Sustainable Development Goals. $^{1} 5$ In 2019, WHO issued guidelines on PA, sedentary behaviour and sleep for children under 5 years of age for the first time. ${ }^{6}$ These guidelines triggered a renewed interest in $\mathrm{PA}$ and provided an opportunity for representatives to reflect on the progress of national actions to promote PA in their respective countries. The new 2020 WHO guidelines on PA and sedentary behaviour for children, adolescents, adults and older adults can support action in priority areas for PA promotion outlined in the GAPPA as well as regional strategies. These areas, such as primary healthcare, education at all levels, workplaces, community structures and partnerships with the private sector and non-traditional actors, are thus better equipped to implement interventions with evidence-based recommendations on the optimal dose of PA for selected population groups and settings. The guidelines provide the basis for WHO Member States to tailor their existing national PA guidelines or establish PA guidelines for the first time, with full support from WHO.

The strategic approach of WHO regional and country offices to increase PA levels varies. Great efforts have been made in the areas of data collection, promoting PA in different settings, and strengthening multisectoral collaboration with multiple stakeholders. However, PA levels are declining in many countries, and sittingtime is alarmingly increasing. ${ }^{78}$ Important discrepancies are found between countries as social determinants, urban environments and opportunities for PA in daily life play a major role in PA, and these factors differ depending on the country context.

The launch of the new global PA guidelines will increase political traction and mobilise action to promote PA in countries around the world. Due to responses to COVID-19 pandemic with wide-spread quarantine, social-distancing measures, closure of recreational amenities and travel restrictions, there is even greater interest and need for countries to support active mobility and provide more opportunities for PA in open spaces and provide online services to increase PA. ${ }^{910}$

The promotion of PA requires multisectoral and integrated collaboration and partnership beyond the health sector to reach those who are less physically active, such as women, older adults and urban populations. The challenge is to coordinate laws, policies and implementation in countries to achieve an overall increase in population levels of PA. Increasing PA requires building back better through whole-of-government approaches 
by multiple sectors and stakeholders and identifying and using synergies with relevant ministries to promote PA. We aim to ensure that PA becomes or remains an integral part of public security, road safety, environmental health, education, transportation, and urban and rural development.

Contributors All individuals contributed to the drafts and all have subsequently contributed. Therefore the authorship is in alphabetical order.

Funding The authors have not declared a specific grant for this research from any funding agency in the public, commercial or not-for-profit sectors.

Competing interests None declared.

Patient consent for publication Not required.

Provenance and peer review Commissioned; internally peer reviewed.

(C) Author(s) (or their employer(s)) 2020. No commercial re-use. See rights and permissions. Published by BMJ.

A Check for updates
To cite Hämäläinen R-M, Breda J, da Silva Gomes F, et al. Br J Sports Med 2020;54:1449-1450.

Accepted 6 October 2020

Br J Sports Med 2020;54:1449-1450.

doi:10.1136/bjsports-2020-103531

\section{ORCID iDs}

Riitta-Maija Hämäläinen http://orcid.org/0000-00018951-7206

Romeu Mendes http://orcid.org/0000-0002-3806-438X

\section{REFERENCES}

1 World Health Organization. Global action plan on physical activity 2018-2030: more active people for a healthier world. Geneva World Health Organization; 2018.

2 World Health Organization. Global recommendations on physical activity for health. Geneva World Health Organization; 2010.

3 Kyu HH, Bachman VF, Alexander LT, et al. Physical activity and risk of breast cancer, colon cancer, diabetes, ischemic heart disease, and ischemic stroke events: systematic review and dose-response metaanalysis for the global burden of disease study 2013. BMJ 2016;354:i3857.

4 Pedersen BK, Saltin B. Exercise as medicine - evidence for prescribing exercise as therapy in 26 different chronic diseases. Scand J Med Sci Sports 2015;25 Suppl 3:1-72.

5 ISPAH International Society for Physical Activity and Health. The Bangkok Declaration on physical activity for global health and sustainable development. $\mathrm{Br} J$ Sports Med 2017;51:1389-91.

6 World Health Organization. WHO guidelines on physical activity, sedentary behaviour and sleep for children under 5 years of age. Geneva World Health Organization; 2019.

7 Guthold R, Stevens GA, Riley LM, et al. Worldwide trends in insufficient physical activity from 2001 to 2016: a pooled analysis of 358 population-based surveys with 1.9 million participants. Lancet Glob Health 2018;6:e1077-86.

8 Guthold R, Stevens GA, Riley LM, et al. Global trends in insufficient physical activity among adolescents: a pooled analysis of 298 population-based surveys with 1.6 million participants. Lancet Child Adolesc Health 2020;4:23-35.

9 Tison GH, Avram R, Kuhar P, et al. Worldwide effect of COVID-19 on physical activity: a descriptive study. Ann Intern Med 2020. doi:10.7326/M20-2665. [Epub ahead of print: 29 Jun 2020].

10 Kluge HHP, Wickramasinghe K, Rippin HL, et al. Prevention and control of non-communicable diseases in the COVID-19 response. Lancet 2020;395:1678-80. 